\title{
Plasma BNP as a Biomarker for Clinical Staging of Heart Failure
}

\author{
MM Hoque ${ }^{1}$, S Shafiullah ${ }^{2}$, P Sultana ${ }^{1}$ \\ ${ }^{1}$ Department of Biochemistry, BSMMU, ${ }^{2}$ Department of Biochemistry, \\ Shaheed Suhrawardi Medical College.
}

\begin{abstract}
Keywords: $\quad$ Background: Accurate diagnosis and clinical staging of heart failure (HF) is essential for its proper $B N P$, Heart failure, Biomarker.

Abstract: management and logical drug therapy to reduce morbidity and mortality. On this perspective researcher are in search of a good biomarker as complementary to the clinical parameters to improve the performance of HF diagnosis and its clinical staging. B-type natriuretic peptide (BNP) secreted by cardiac ventricles in HF has emerged as a new promising biomarker in this regard. Objective of the study was evaluation of plasma BNP concentration in relation to the severity of HF and its use as a biomarker for clinical staging of $\mathrm{HF}$.

Methods: In a cross sectional study 100 HF cases diagnosed by clinical parameters and echocardiography were enrolled and sub grouped into NYHA classes (I, II, II \& IV) depending on clinical severity and functional limitations. Plasma BNP measured in all study subjects and summarized in each of these sub groups.

Results: Median plasma BNP concentration in NYHA class-I, II, III \& IV found to be 82.7, 267.2, 694.8 \& $1530.4 \mathrm{pg} / \mathrm{ml}$ respectively with progressive rising trend and at $95 \%$ CI level the plasma BNP in different sub groups were 64.5-112.7, 214.3-293.5, 626.4-902.4 \& 1443.1-2384.4pg/ml respectively.

Conclusion: Plasma BNP concentration increases progressively with increasing severity of HF to make it to be used for clinical staging of the disease. In mild, moderate and severe HF plasma BNP proposed to be 100-460, 460-1170 and >1170pg/ml respectively.
\end{abstract}

(Cardiovasc.j. 2010; 2(2) : 142-146)

\section{Introduction:}

Heart failure is a common, highly morbid cardiovascular disorder associated with perturbations in cardiac structure and function; culminating to the failure of heart to meet up the perfusion demand of peripheral tissues.

Incidence of heart failure is gradually increasing. It is nearly as common as diabetes in older adults, occurring in $2 \%$ of the adult population and raising to $3 \%$ in adults over 75 years age. About $35 \%$ of these patients hospitalize annually and $50 \%$ die within 5 years. ${ }^{1}$

For individuals more than 40 years, the life time risk of developing heart failure has been estimated to about $20 \%$ for both sexes. The incidence of heart failure is highest in peoples older than 65 years. This segment of population is growing rapidly, ensuring an epidemic of heart failure that will continue to grow as the population ages. ${ }^{2}$ According to Boon et al. ${ }^{3}$ the prevalence of heart failure rises from around $1 \%$ in the age group $50-59$ years to about $5-10 \%$ among those aged $80-89$ years.

The most common cause of heart failure is the ischemic heart disease. Due to the seminal improvements in diagnosis and treatment of patients with Acute Coronary Syndrome (ACS) in recent past, more patients are now surviving ACS than in previous decades and are left at risk for developing heart failure. ${ }^{4}$ Half of patients carrying a diagnosis of $\mathrm{HF}$ die within 4 years and in patients with severe $\mathrm{HF}$ more than $50 \%$ die within 1 year. ${ }^{5}$ So heart failure is dreadful condition as far as prognosis is concerned. Good management of heart failure depends on accurate etiological diagnosis and clinical staging because a clear understanding of pathophysiology with etiology and clinical staging is essential to logical drug therapy. ${ }^{3}$

Traditionally diagnosis of heart failure is clinical one based on signs, symptoms, chest radiographs, and response to therapy. Since most of these

Address of Correspondence: Prof. Md. Mozammel Hoque, Department of Biochemistry, Bangabandhu Sheikh Mujib Medical University, Dhaka, Bangladesh. 
findings are non-specific, diagnosis of heart failure is often extremely difficult and both under and over diagnosis is common especially in elderly population, obese and patients with underlying lung disease. ${ }^{6}$

Until now echocardiogram is regarded as the gold standard laboratory tool to diagnose heart failure in spite of its limitations. Echocardiogram is mostly concerned to characterized the specific structural and functional abnormalities associated with the syndrome but do not determine the diagnosis of heart failure. ${ }^{2}$

Therefore, health personnel were searching for inexpensive, specific, sensitive, readily available and easily interpretable diagnostic aid to diagnose heart failure irrespective of underling etiopathophysiology. Cardiac natriuretic hormones have been researched for such a diagnostic value. On this perspective B-type natriuretic peptide (BNP) has come to light as an ideal biomarker with high diagnostic and prognostic weight for heart failure patients regardless of its type and causes. The clinical staging of heart failure with respect to its severity is very much important for proper management of HF. Until now it is based primarily on clinical parameters. NYHA (New York Heart Association) on the basis of some clinical parameter has developed a system for heart failure staging that ranges from least to most severe forms as class-I to IV which is popularly known as NYHA classes of HF. ${ }^{7}$ Researchers are searching for a good biomarker for clinical staging of $\mathrm{HF}$ as a complementary or supplementary to NYHA class. B-type natriuretic peptide (BNP) is a cardiac neurohormone specifically secreted from the cardiac ventricles in response to ventricular volume expansion, pressure overload and resultant increased wall tension. ${ }^{8}$ The rise of ventricular volume and pressure overload are positively correlated with BNP release. ${ }^{4}$

The persistent progressive cardiac congestion generates mounting myocardial stress leading to increased BNP synthesis. Plasma BNP concentration increases in heart failure in proportion to its severity. ${ }^{9}$ In patients with left ventricular dysfunction (LVD) plasma level of BNP increases that correlate with the NYHA class, as well as with prognosis. ${ }^{4}$ So BNP has come to the surface as a new promising biomarker for clinical staging of HF. The increasing myocardial stress parallels \& keeps pace with the rising BNP production. So BNP seems to be positively correlated with the severity of $\mathrm{HF}$ which could be exploited for clinical staging, risk assessment and risk stratification of heart failure. Plasma BNP measurement is not so expensive, readily available, easily interpretable and found to be suited very much for the poor patients like ours. The availability of this simple blood test could dramatically influence the landscape of $\mathrm{HF}$ management and its risk stratification. On our perspective this will facilitate the rapid correct clinical staging of $\mathrm{HF}$ to reduce its morbidity and mortality in our population.

Large body of evidences is now in a consensus to use plasma BNP as a diagnostic and prognostic biomarker for heart failure patients but its use as a marker for clinical staging of HF is yet to be established conclusively. So, we have decided to evaluate the association of plasma BNP with respect to clinical staging and risk stratification of HF patient.

\section{Materials and Methods:}

In a cross sectional study $100 \mathrm{HF}$ patients with mean age $41.1 \mathrm{yr}$ (10-70 yr) male-61 and female-39 were selected from the cardiology department of Bangabandhu Sheikh Mujib Medical University (BSMMU) hospital through non random sampling during the period of July/2007 to June/2008. All study subjects were free from ischemic heart disease renal failure, non cardiac fluid overload, thyroid disorders and liver diseases. Ethical clearance for the study was taken from the central ethical committee BSMMU and informed written consent of all study subjects were taken prior to their enrollment. Diagnosis of HF was made on the basis of clinical and echocardiographic findings and then cases were sub- grouped based on their clinical severity and functional limitation into NYHA classification (class-I, II, II, IV). For all study subjects preformed questionnaire was used to collect data and blood sample was collected aseptically and eventually plasma was separated for measurement of plasma BNP by microparticle enzyme immunoassay (MEIA) principle. ${ }^{10}$ Plasma BNP concentration were summarized in each of these sub-groups and compared among the sub- 
groups in an attempted to associate the progressive rising relationship of plasma BNP concentrations with increasing severity of $\mathrm{HF}$ and to categorize the clinical sub-groups based on plasma BNP. Data were analyzed using SPSS (Version 12.0 for windows). Plasma BNP among the subgroups were compared by one any ANOVA and multiple comparison test and $\mathrm{p}<0.05$ was considered as statistically significant. In each of the NYHA subgroups of HF plasma BNP concentration was determined at $95 \%$ confidence interval to differentiate the clinical subgroups among themselves.

\section{Results and Observations:}

Median plasma BNP concentration in NYHA classI, II, III \& IV found to be 82.7, 267.2, 694.8 \& 1530.4 $\mathrm{pg} / \mathrm{ml}$ respectively with progressive rising trend and at 95\% CI level the plasma BNP in different sub groups were 64.5-112.7, 214.3-293.5, 626.4902.4 \& 1443.1-2384.4 pg/ml respectively. Plasma BNP concentration was proposed in different sub groups bridging the gaps between consecutive sub groups and finally plasma BNP concentration in mild, moderate and severe HF proposed to be $100-$ $460,460-1170$ and $>1170 \mathrm{pg} / \mathrm{ml}$ respectively.

Table-I

Plasma BNP concentration in different clinical subgroups of $\mathrm{HF}$

\begin{tabular}{lcccc}
\hline NYHA subgroups & Total number & \multicolumn{2}{c}{ Plasma BNP $(\mathrm{pg} / \mathrm{ml})$} & 95\% CI \\
\cline { 3 - 4 } & & Mean & Median & $(\mathrm{m} \pm 1.96 \mathrm{SE})$ \\
\hline Class-I (mild HF) & 16 & 88.6 & 82.7 & $64.5-112.7$ \\
Class-II (mild HF) & 28 & 253.9 & 267.2 & $214.3-293.5$ \\
Class-III (moderate HF) & 29 & 764.4 & 694.8 & $626.4-902.4$ \\
Class-IV (Severe HF) & 27 & 1913.5 & 1530.4 & $1443.1-2384.0$ \\
\hline
\end{tabular}

Table II

Comparison of plasma BNP concentration among the clinical subgroups of $H F$

\begin{tabular}{lccc}
\hline & Comparison between subgroups & & Level of significance (p-value) \\
\hline Class I & VS & Class II & $>0.05$ \\
Class I & VS & Class III & $<0.05$ \\
Class I & VS & Class IV & $<0.001$ \\
Class II & VS & Class III & $<0.05$ \\
Class II & VS & Class IV & $<0.001$ \\
Class III & VS & Class IV & $<0.001$ \\
\hline
\end{tabular}

p-value reached by ANOVA followed by bonferoni (multiple comparisons) test

Table-III

Proposed plasma BNP concentration in different clinical subgroups (NYHA classes) of HF

\begin{tabular}{lccc}
\hline NYHA & Plasma BNP $(\mathrm{pg} / \mathrm{ml})$ & \multicolumn{2}{c}{ Proposed Plasma BNP $(\mathrm{pg} / \mathrm{ml})$} \\
\cline { 3 - 4 } classes & at 95\% CI & $\begin{array}{c}\text { Bridging gaps } \\
\text { between consecutive classes } \\
\text { with half way of gaps } \\
\text { on either side }\end{array}$ & $\begin{array}{c}\text { Compromising class limits } \\
\text { to nearest zero or five } \\
\text { with cut off value 100pg/ml }\end{array}$ \\
\hline I & $64.5-112.7$ & $64.5-163.5$ & $100-165$ \\
II & $214.3-293.5$ & $163.5-459.95$ & $165-460$ \\
III & $626.4-902.4$ & $459.95-1172.75$ & $460-1170$ \\
IV & $1443.1-2384.0$ & $1172.75-2384.0$ & $>1170$ \\
\hline
\end{tabular}


Table-IV

Proposed plasma BNP concentration in different clinical types of Heart Failure

\begin{tabular}{lc}
\hline Clinical types & $\begin{array}{c}\text { Proposed plasma } \\
\text { BNP }(\mathrm{pg} / \mathrm{ml})\end{array}$ \\
\hline Mild HF (NYHA-I \& II) & $100-460$ \\
Moderate HF (NYHA-III) & $460-1170$ \\
Severe HF (NYHA-IV) & $>1170$ \\
\hline
\end{tabular}

\section{Discussion:}

Plasma BNP concentration in clinical sub-groups (NYHA class I to NYHA class IV) of our HF cases found to be gradually increasing with the lowest concentration in class I and highest concentration in class IV, indicating the increasing plasma BNP concentration with increasing severity of HF. Our findings of gradually increasing plasma BNP concentration with increasing severity of $\mathrm{HF}$ found consistent with those of other researchers. ${ }^{4,11,12,13,14}$ Wieczorek et al. ${ }^{11}$ found plasma BNP concentration to be $83.1 \mathrm{pg} / \mathrm{ml}$ (lowest) in class-I, $235 \mathrm{pg} / \mathrm{ml}$ in class II, $459 \mathrm{pg} / \mathrm{ml}$ in class III and $1119 \mathrm{pg} / \mathrm{ml}$ (highest) in class-IV. Again, Maisel et al. ${ }^{4}$ found the mean plasma BNP concentration progressively increasing form 244 $\mathrm{pg} / \mathrm{ml}$ to $389 \mathrm{pg} / \mathrm{ml}$, to $640 \mathrm{pg} / \mathrm{ml}$ and finally to 817 $\mathrm{pg} / \mathrm{ml}$ in NYHA class I, II, III and IV respectively according to the rising severity of HF. Whereas, Dao et al. ${ }^{15}$ focused on the plasma BNP more than $100 \mathrm{pg} / \mathrm{ml}$ in mild $\mathrm{HF}$, more than $500 \mathrm{pg} / \mathrm{ml}$ in moderate $\mathrm{HF}$ and more than $1000 \mathrm{pg} / \mathrm{ml}$ in severe HF. Rahman, ${ }^{14}$ in his study showed median plasma BNP concentration in NYHA class I, II, III and IV to be $141.04 \mathrm{pg} / \mathrm{ml}, 270.53 \mathrm{pg} / \mathrm{ml}, 717.97 \mathrm{pg} / \mathrm{ml}$ and $1602.48 \mathrm{pg} / \mathrm{ml}$ respectively. In all these studies including ours, although the value of plasma BNP concentration in different NYHA subgroups showed a bit variation among the studies but in every case rising trend of plasma BNP found with increasing severity of $\mathrm{HF}$ and in some cases the values of plasma BNP in different subgroups found well harmonious with those of ours.

The mean plasma BNP concentrations were compared among the clinical subgroups of NYHA stage. Between the NYHA class I and class II difference was not significant but plasma BNP concentration found significantly $(\mathrm{P}<0.05)$ higher in NYHA class III compared to class I and II; and in class IV $(\mathrm{P}<0.001)$ compared to class I, II and
III. However, Tsutamoto et al. ${ }^{16}$ observed plasma BNP concentration significantly higher in classIV compared to class II and III but they found no difference between class II and III. Dao et al. ${ }^{15}$ and Maisel et al. ${ }^{4}$ found significantly higher plasma BNP concentration in class-IV compared to class III, in class III compared to class II and in class II compared to class I. Similar finding also revealed from the study done by Rahman. ${ }^{14}$ All these studies are well in agreement with that of ours.

In this study, we have used mean plasma BNP concentration in an attempt to categorize different clinical subgroups of $\mathrm{HF}$ at $95 \%$ confidence level. At $95 \%$ confidence level the range of plasma BNP concentration in NYHA class I, II, III and IV found to be $64.5-112.7 \mathrm{pg} / \mathrm{ml}, 214.3-293.5 \mathrm{pg} / \mathrm{ml}, 626.4$ $902.4 \mathrm{pg} / \mathrm{ml}$ and $1443.1-2384.0 \mathrm{pg} / \mathrm{ml}$ respectively. On arbitrary mathematical point of view considering the half way of the numerical gaps between two consecutive class on either side of the class we like to propose the plasma BNP concentration in class I, class II, class III and classIV to be $64.5-163.5,163.5-459.95,459.95-1172.75$ and $1172.75-2384.0 \mathrm{pg} / \mathrm{ml}$ respectively. On rounding the class limit to nearest zero or five and considering the cut off point of plasma BNP more than $100 \mathrm{pg} / \mathrm{ml}$ for diagnosis of HF; our final recommendation regarding plasma BNP in NYHA class I, class II, class III and class IV is 100-165, 165-460, 460-1170 and more than $1170 \mathrm{pg} / \mathrm{ml}$ respectively. Findings of Wieczorek et al. ${ }^{11}$ and Rahman ${ }^{14}$ passively support this proposition.

An alternative way of clinical sub-grouping of $\mathrm{HF}$ is mild, moderate and severe. Mild HF is equivalent to NYHA class-I and II, whereas moderate and severe HF are equivalent to NYHA class III and IV respectively. ${ }^{17}$ In our study we have got no difference between NYHA class-I and II with regard to plasma BNP. So on merging class I and class II as mild HF we proposes plasma BNP concentration in mild, moderate and severe HF to be 100-460, 460-1170 and more than $1170 \mathrm{pg} / \mathrm{ml}$ respectively. Some author proposes mild HF with plasma BNP 300-600 pg/ml, moderate HF with plasma BNP 600-900 pg/ml and severe HF with plasma $\mathrm{BNP} \geq 900 \mathrm{pg} / \mathrm{ml}^{18}$

\section{Conclusion:}

In $\mathrm{HF}$ progressive cardiac congestion generates mounting myocardial stress leading to BNP 
synthesis from cardiac ventricles. The rising trend of plasma BNP found to be consistent with the increasing severity of HF. So plasma BNP can be used as a biomarker for clinical staging of HF. This study proposes the plasma BNP concentration in mild, moderate and severe HF to be 100-460, 4601170 and $>1170 \mathrm{pg} / \mathrm{ml}$ respectively.

\section{Acknowledgement:}

The authors are grateful to Noor Md. Rahmatullah, Professor Dept. of Statistics, Sher-e-Bangla Agriculture University, Sher-e-Bangla Nagar, Dhaka for his cooperation in statistical analysis.

Conflict of Interest - None.

\section{References:}

1. Frank, J. Congestive heart failure and brain natriuretic peptide. PSA Consult 2002; 14: 4-5.

2. Lloyd-Jones, DM. The risk of congestive heart failure: Sobering lessons from the Framingham Heart Study. Curr Cardiol Rep 2001; 3(3):184-190.

3. Boon, NA, Fox, KAA, Bloomfield, P, Bradbury, A. Cardiovascular disease. In Haslett, C, Chilvers, ER, Boon, NA, Colledge, NR (eds), Davidson's Principles and practice of medicine, edn. $19^{\text {th }}$ edn, Churchill Livingstone, Edinburgh, 2002:381-385.

4. Maisel, AS, Krishnaswamy, P, Nowak, RM, McCord, J, Hollandar, JE, Duc, P et al. Rapid measurement of Btype natriuretic peptide in the emergency diagnosis of heart failure. N Engl J Med 2002; $347 \quad$ (3):161-167.

5. Swedberg, K, Cleland, J, Dargie, H, Drexler, H, Follath, F, Komajda, M, Tavazzi, L, Smiseth, OA. Guidelines for the diagnosis and treatment of chronic heart failure: executive summary (update 2005). European heart Journal 2005; 26:1115-1140.

6. Redfield MM. The breathing not proper trial: enough evidence to change heart failure guidelines? J Card Fail 2002; 8:120-123.

7. Bluestein, BI, Despres, N, Belenky, A, Ghani, F, Armstong, EG BNP in the diagnosis of heart failure. Retrieved May 22, 2008 from http://laboratorymanager.advanceweb.com/editorial/content.
8. McCullugh, PA, Nowak, RM, McCord, J, Hollander, JE, Herrmann, HC, Steg, PG et al. B-type natriuretic peptide and clinical judgment in emergency diagnosis of heart failure. Circulation 2002; 1.106: 416-422.

9. Schrier, RW, Abraham, WT. Hormones and hemodynamics in heart failure. N Engl J Med 1999; 341(8): 577-585.

10. Axis-Shield Diagnostics. Estimation of plasma BNP. In: Operation manual for AxSYM. BNP, Abbott Laboratories, USA. 2003,

11. Wieczorek, SJ, Wu, AHB, Christenson, R, Krishnaswamy, P, Gottlieb, S, Rosano, T et al. A rapid B-type natriuretic peptide assay accurately diagnoses left ventricular dysfunction and heart failure: a multicenter evaluation. Am Heart J 2002;144: 834-839.

12. Yoshimura, M, Yasue, H, Okumura, K, Ogawa, H, Jougasaki, M, Mukoyama, M, Nakao, K, Imura, H. Different secretion patterns of natriuretic peptide and brain natriuretic peptide in patients with congestive heart failure. Circulation 1993; 87: 464-469.

13. Winter, WE, Elin, RJ. The role and assessment of ventricular peptides in heart failure. Clin Lab Med 2004; 24(1): 235-274.

14. Rahman, MS. Role of plasma BNP (B-type natriuretic peptide) and cTn-I (cardio specific troponin-I) as biomarkers in heart failure', MD Thesis, BSMMU, Dhaka. 2005,

15. Dao, Q, Krishnaswamy, P, Kazanegra, R, Harrison, A, Amirnovin, R, Lenert, L, Clopton, P, Alberto, J, HIavin, $\mathrm{P}$, Maisel, AS. Utility of B-type natriuretic peptide in the diagnosis of congestive heart failure in an urgentcare setting. J Am Coll Cardiol 2001; 37: 379-385.

16. Tsutamoto, T, Wada, A, Maeda, K, Hisanaga, T, Maeda, Y, Fukai, D, Ohnishi, M, Sugimoto, Y, Kinoshita, M. Attenuation of compensation of endogenous cardiac natriuretic peptide system in chronic heart failure. Circulation 1997; 96: 509-516.

17. Brookes, L. Incorrect classification of patients by the AHA/ACC stages of heart failure. Retrieved February 29, 2008 from http://www.medscape.com/viewarticle/ 490041.

18. Maria, GE. Brain Natriuretic Peptide (BNP) Test. Retrieved February 23, 2008 from http:// www.webmd.com/heart-disease/ brain-natriureticpeptide-bnp-t. 